Research Paper

\title{
Stereotactic Body Radiotherapy (SBRT) for Intrahepatic and Hilar Cholangiocarcinoma
}

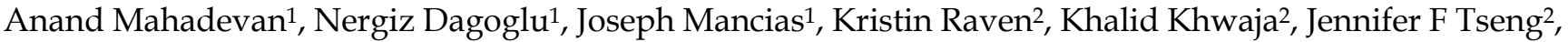 \\ Kimmie $\mathrm{Ng}^{3}$, Peter Enzinger ${ }^{3}$, Rebecca Miksad ${ }^{4}$, Andrea Bullock ${ }^{4}$, Amy Evenson ${ }^{2} \llbracket$ \\ 1. Department of Radiation Oncology, Harvard Medical School, Boston, Massachusetts, USA \\ 2. Department of Surgery, Harvard Medical School, Boston, Massachusetts, USA \\ 3. Department of Medical Oncology, Dana Farber Cancer Institute, Harvard Medical School, Boston, Massachusetts, USA \\ 4. Department of Medical Oncology, Beth Israel Deaconess Medical Center, Harvard Medical School, Boston, Massachusetts, USA \\ $\triangle$ Corresponding author: Anand Mahadevan MD, Department of Radiation Oncology, Beth Israel Deaconess Medical Center, 330 Brookline Avenue, \\ Boston, MA 02215. USA. Tel: +1 617667 2345; Fax +1 617667 4990; Email: amahadev@bidmc.harvard.edu
}

() 2015 Ivyspring International Publisher. Reproduction is permitted for personal, noncommercial use, provided that the article is in whole, unmodified, and properly cited. See http://ivyspring.com/terms for terms and conditions.

Received: 2015.01.27; Accepted: 2015.02.09; Published: 2015.08.01

\begin{abstract}
Background: Unresectable intrahepatic and hilar cholangiocarcinomas carry a dismal prognosis. Systemic chemotherapy and conventional external beam radiation and brachytherapy have been used with limited success. We explored the use of stereotactic body radiotherapy (SBRT) for these patients.

Methods: Patients with unresectable intrahepatic or hilar cholangiocarcinoma or those with positive margins were included in this study. Systemic therapy was used at the discretion of the medical oncologist. The Cyberknife ${ }^{\mathrm{TM}}$ stereotactic body radiotherapy system used to treat these patients. Patients were treated with three daily fractions. Clinical and radiological follow-up were performed every three months.

Results: 34 patients ( 16 male and 18 female) with 42 lesions were included in this study. There were 32 unresectable tumors and two patients with resected tumors with positive margins. The median SBRT dose was 30Gy in three fractions. The median follow-up was 38 months (range 8-71 months). The actuarial local control rate was $79 \%$. The median overall survival was 17 months and the median progression free survival was ten months. There were four Grade III toxicities (12\%), including duodenal ulceration, cholangitis and liver abscess.

Conclusions: SBRT is an effective and reasonably safe local therapy option for unresectable intrahepatic or hilar cholangiocarcinoma.
\end{abstract}

Key words: stereotactic body radiotherapy, cholangiocarcinomas

\section{Introduction}

Cholangiocarcinomas, the second most common primary malignancy of the liver, are a heterogeneous group of malignancies ranging from intrahepatic to hilar, distal biliary and ampullary cancers $(1,2)$. They are uncommon tumors with an age-adjusted incidence ratio of 0.92 per 100,000 in the US(3). Overall, intrahepatic and hilar cancers, including unresectable and advanced disease, carry a dismal prognosis with a 5-10\% 5-year survival(4), with curative surgery providing the best outcomes. However, between
$50-90 \%$ of patients present with unresectable disease at presentation,(6) and their median survival is often less than a year. Despite advances in diagnostic and surgical techniques, some patients are left with positive margins, and their outcome is poor without additional therapy $(1,4,5,7)$. Systemic therapy and conventional radiotherapy has remained the standard of care for these patients, however with limitations and toxicity(8-10). These approaches provide local control in two-thirds of patients within their median overall 
survival time of 8-12 months(4).

The main limitation of conventional external beam radiotherapy has been the tolerance of the liver and the gastrointestinal tract adjacent to the tumor. Highly conformal stereotactic body radiotherapy (SBRT) has been used safely and effectively in hepatobiliary and pancreatic cancers(11-13). Another rationale for hypofractionated SBRT is that it does not significantly interrupt systemic chemotherapy(14). Hence we explored the role of SBRT in localized non-metastatic hilar or intrahepatic cholangiocarcinoma.

\section{Materials and Methods}

\section{Patients and Lesions}

Our institutional IRB approved database (DFHCC 09-451) was retrospectively reviewed. Intrahepatic or hilar cholangiocarcinoma patients who were treated with SBRT were analyzed. Thirty-four patients with 42 treatments were identified between February 2006 and February 2014. Twenty-nine patients had primarily non-metastatic unresectable disease, three were medically inoperable and two had positive margins. There were 31 intrahepatic and 11 hilar lesions. Eighteen patients received systemic chemotherapy. Four patients had Gemcitabine alone and the rest received gemcitabine and cisplatin at the discretion of the medical oncologist.

\section{SBRT}

At least two gold fiducial markers were placed percutaneously, intraoperatively or endoscopically in or near the tumor at least a week prior to the procedure. All patients underwent computed tomography (CT) simulation in supine position with VacLoc ${ }^{\mathrm{TM}}$ body immobilization system. Intravenous and barium contrast agent was used during CT planning and 1 $\mathrm{mm}$ axial $\mathrm{CT}$ images were obtained in the region of interest. The gross tumor volume (GTV) and normal structures were contoured on axial CT images. The Multiplan ${ }^{\mathrm{TM}}$ software was used for treatment planning and all patients were treated with the Cyber$\mathrm{knife}^{\mathrm{TM}}$ system with real time fiducial tracking. The dose fractionation scheme was individualized based on normal tissue constraints to bowel and liver related to tumor volume and location of the tumor. The normal tissue tolerance parameters relevant in the upper abdomen in this study are for bowel (small bowel, hepatic flexure and stomach) and liver. In general, we use our institutional protocols for maximum point doses and dose volume histogram (DVH) constraints to these structures: bowel: 24 Gy in three fractions to no more than a third of the circumference of the bowel with a maximum point dose of 30 Gy in 3 fractions; Liver: at least $750 \mathrm{cc}$ of healthy Liver V21 (Volume receiving more than 21Gy) is $<30 \%$ and V15 (Volume receiving more than $15 \mathrm{~Gy}$ ) is less than $50 \%$. Three daily fractions were typically used, given between chemotherapy cycles when systemic therapy was used. All patients were premedicated with lorazepam, proton pump inhibitors and prochlorperazine.

\section{Follow-up}

Follow-up data included status of disease, date of progression if any, site of failure and last follow up date. CT imaging and CA19-9 tumor markers evaluated tumor response to treatment. Local failure was defined as increase in the sum of the longest diameter of target lesion. If a new lesion developed in the liver but outside the radiation field, it was interpreted as failure outside the treated area. Acute and late toxicities were defined as symptoms that develop within three months after SBRT or later, respectively.

\section{Statistics}

Descriptive statistics was used to analyze patient, tumor, and treatment characteristics. Kaplan-Meier analysis was performed to report survival and local control outcomes. GraphPad Prism Version 6.0.c software GraphPad Software, Inc., La Jolla, CA, USA) was used for statistical analysis.

\section{Results}

\section{Patient and Treatment Characteristics}

Thirty-four patients with 42 lesions were treated with SBRT using the CyberKnife ${ }^{\mathrm{TM}}$ for intrahepatic or hilar cholangiocarcinoma at our center between February 2006 and February 2014. Sixteen males and 18 females were included. The median age at the time of treatment was 72 years (range 38-94 years).

Twenty-nine patients had unresectable disease, three were medically inoperable and two had positive margins. There were 31 intrahepatic lesions and 11 hilar cholangiocarcinomas. Twenty-one (62\%) patients had biliary stents.

The patient and treatment characteristics are described in Table 1.

The medial tumor volume was 63.8cc (range $5.88-500.56 \mathrm{cc}$ ). The median prescription dose was 30 Gy in three fractions to the median $75 \%(67-87 \%)$ isodose line. The average maximum dose was $40 \mathrm{~Gy}$ and Conformality Index (CI) and the Homogeneity Index (HI) was 1.28 and 1.33 respectively.

The SBRT treatment parameters are described in Table 2. A representative treatment plan for hilar cholangiocarcinoma is shown in Figure 1.

\section{Efficacy}

Median follow-up was 38 months (8 to 71 months). The overall median survival after SBRT was 
17 months. The actuarial 1-year, 2-year and 4-year survival rates were $58 \%, 31 \%$ and $19 \%$ respectively. The 1-year and 4-year actuarial local control rates were $88 \%$ and $79 \%$. Median progression-free survival was 10 months after SBRT. Four patients failed in the liver outside the treatment area, and nine patients developed distant metastasis. The Kaplan-Meier actuarial local control and overall survival is shown in Figure 2.

\section{Toxicity}

Most patients developed fatigue. Six patients had symptomatic nausea requiring medication $(18 \%$ Grade II toxicity). There were four Grade III adverse effects $(12 \%)$. Two patients developed duodenal ulceration, one patient had cholangitis and one patient developed a liver abscess. There was no Grade IV or higher toxicity.
Table 1: Patient and Treatment Characteristics

\begin{tabular}{lll}
\hline $\begin{array}{l}\text { Patient and initial treatment characteristics. (Pa- } \\
\text { tients=34,lesions=42) }\end{array}$ & Number (\%) \\
\hline Sex(M/F) & & $16 / 18$ \\
Age & Yes & $72(38-94)$ \\
Biliary Stent & No & $13(38.2 \%)$ \\
\multirow{2}{*}{ Additional Treatment } & Chemotherapy & $21(61.8 \%)$ \\
& None & $18(52.9 \%)$ \\
& Surgery & $9(26.6 \%)$ \\
& Chemoembolization & $3(8.8 \%)$ \\
Surgery & Surgery+Chemotherapy & $1(2.9 \%)$ \\
& Resected with positive margins & $3(8.8 \%)$ \\
& Unresectable & $2(5.9 \%)$ \\
& \multicolumn{1}{c}{ By Radiologic Criteria } & $7(20.3 \%)$ \\
& At Exploration & $22(64.7$ \\
Location & Medically Inoperable & $38.8 \%)$ \\
& Intrahepatic & $31(73.8 \%)$ \\
& Intra+Extrahepatic & $9(21.4 \%)$ \\
& Hilar & $2(4.8 \%)$ \\
\hline
\end{tabular}

Table 2: SBRT Treatment Characteristics

\begin{tabular}{lll}
\hline & Mean & Range \\
\hline Treatment volume & $63.8 \mathrm{cc}$ & $(5.88-500.56)$ \\
Prescription isodose & $75 \%$ & $(67-87)$ \\
Total SBRT dose & 30 & $(10-45)$ \\
No of fractions & 3 & $(1-5)$ \\
Max dose & 40 & $(13.51-64.29)$ \\
Conformality Index & 1.28 & $(1.10-1.76)$ \\
Homogeneity Index & 1.33 & $(1.30-1.49)$ \\
\hline
\end{tabular}

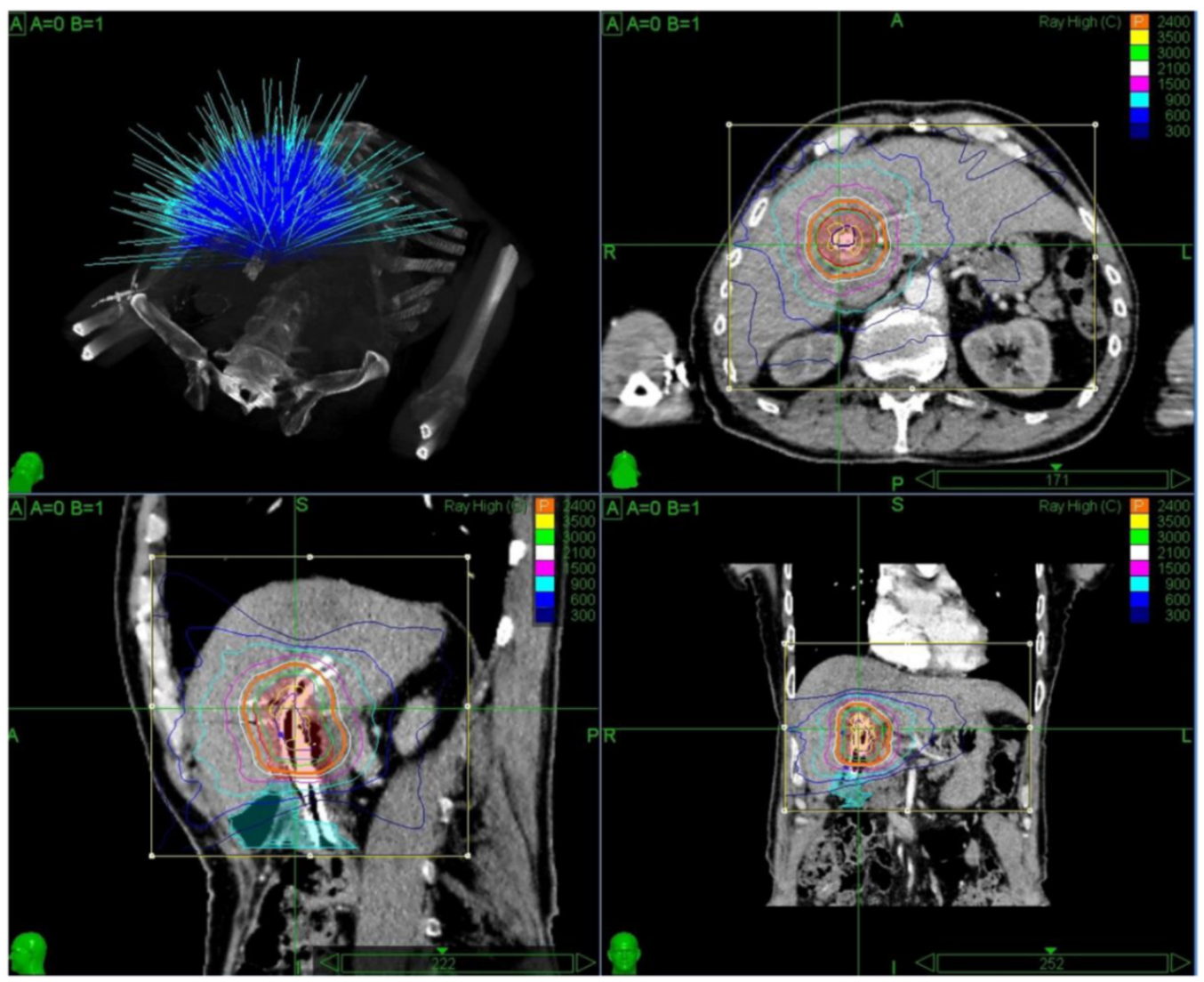

FIGURE 1: Representative treatment plan of a Hilar Cholangiocarcinoma. 


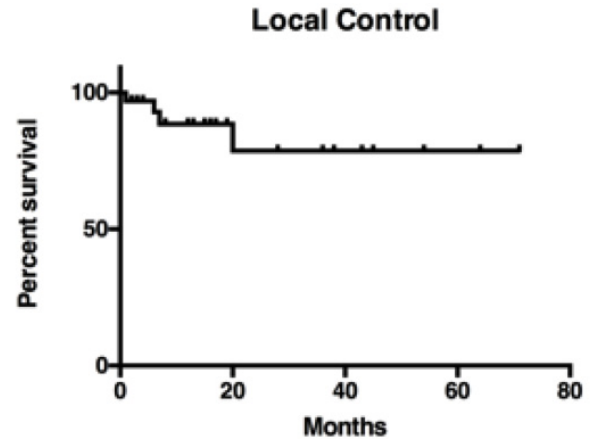

$\begin{array}{llll}\text { No. at Risk } & 34 & 9 & 6\end{array}$
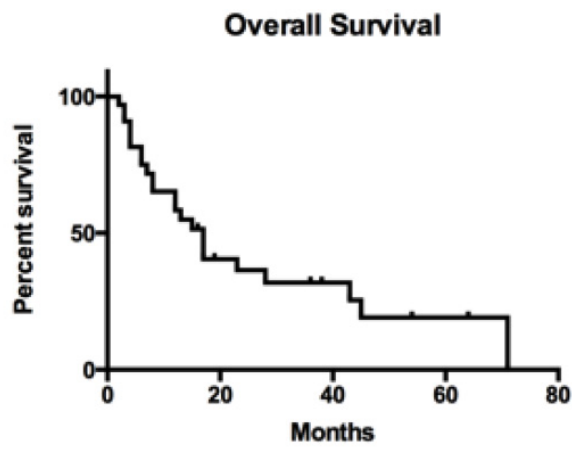

No. at Risk $\quad 34 \quad 11 \quad 6$

FIGURE 2: Actuarial Local Control and Overall Survival.

\section{Discussion}

Complete surgical resection is the only potentially curative treatment for intrahepatic or hilar cholangiocarcinoma. However in non-metastatic disease, the local extent of the disease often precludes safe or margin-negative resection. We have shown that stereotactic body radiotherapy can be a useful local therapeutic modality in this situation.

The reported 5-year survival after potentially curative surgery in all patients can be less than $20 \%$, improving to about $30-60 \%$ with R0 (microscopic margin negative) resection, with median survival times of around 15 and 28 months respectively(15). R0 resection is the major prognostic factor after surgical resection $(15,16)$ and extensive resections including trisegmentectomey(17), and liver transplantation $(6,18)$ have been used to achieve a complete resection. Although surgical resection rates in non-metastatic patients at presentation can be around $60 \%(7)$, about $15-25 \%$ of patients are found to have more extensive disease at laparotomy despite advances in preoperative diagnostic improvements leaving a proportion of patients with R1 or R2 resections(19).

The conventional treatment for unresectable disease or after R1 (microscopic residual) or R2 (macroscopic residual) resections has been radiation therapy with or without systemic chemotherapy. The use of conventional radiation therapy alone was associated with a median survival of around 10 months(20-22). Concurrent chemoradiation with 5 -fluorouracil-based systemic therapy improved median survival to around 15 months(23-25). The addition of brachytherapy appeared to have increased local control rates, without significantly impacting overall survival(26-30). An early EORTC study(31) and many single institution studies demonstrated improved outcomes with the addition of adjuvant post-operative radiation therapy $(32,33)$. In patients with positive margins, adjuvant radiation(34) and the use of postoperative chemoradiation therapy(35) have demonstrated extension of median survival. Based on these data, it is considered standard practice to use chemoradiation in this setting.

Conventional chemoradiation involves up to six weeks of daily radiation with systemic therapy associated with significant toxicity $(8,36)$. Others groups have questioned the value and usefulness chemoradiation in this setting $(8,37)$. Modern systemic therapy regimens appear to have similar overall survival outcomes(10), emphasizing the importance of systemic therapy in this disease. Stereotactic body radiotherapy (SBRT) has been used in upper abdominal malignancies with useful efficacy and tolerability $(11,12,14,38-41)$. It is typically dosed in one to five treatments without interfering with the needed systemic therapy.

We present the largest series of patients with intrahepatic and hilar cholangiocarcinoma treated with SBRT. Other published series and outcomes are reported in Table 3.

With a median follow up of 38 months, our median survival of 17 months and 4-year actuarial local control rate of $79 \%$ compares well with other series. Herfarth et al, Tse et al and Goodman et al published initial reports on 3-10 patients with cholangiocarcinoma among other liver tumors, hypothesizing the feasibility of SBRT in locally advanced cholangiocarcinoma $(40,42,43)$. These reports included no Grade III or more toxicity. Polistina et al reported on a series of 10 patients with Klatskin tumors using SBRT, 30 Gy in 3 fractions, and gemcitabine with excellent outcomes with a median survival of 35.5 months(44). Their series did not include patients with unresectable intrahepatic cholangiocarcinoma. Two patients had duodenal bleeding, one had late duodenal ulceration and two others developed duodenal stenosis. Barney et al reported on 10 patients, with a mix of primary and recurrent tumors treated with SBRT(45). They used a median of five fractions to $55 \mathrm{~Gy}$. With median follow up of 14 months, they reported a 1-year survival of $73 \%$ and $100 \%$ local control in their short follow up. They also reported a case of late biliary stricture and 
death due to liver failure. Welling et al utilized neoadjuvant SBRT, followed by maintenance capecitabine until transplant in 12 patients(46). Six of their patients eventually underwent a liver transplant with five of the six patients showing partial pathological response. There were 11 transplant-associated complications with a 1-year survival of $83 \%$.

The most comparable series to the present study is from Kopek et al (47). The majority of their patients $(26 / 27)$ had Klatskin tumors. They were treated with a fixed prescription of $45 \mathrm{~Gy}$ in three fractions with CTV (Clinical Target Volume) and PTV (Planning Target Volume) expansions, and no respiratory motion management was used during treatment. Their median progression-free and overall survival was 6.7 and 10.6 months respectively. However, six patients developed severe duodenal/pyloric ulceration and nine developed duodenal stenosis. The authors per- formed a dose-volume analysis of the duodenal dose that correlated with toxicity. This is not surprising given the close proximity of the duodenum to hilar tumors. Our results with 12\% long-term Grade III toxicity compares favorably with this and other series. The primary differences which could explain this difference could be the combination of duodenal tolerance-based prescription used in our study and respiratory motion tracking used with the Cyberknife ${ }^{\mathrm{TM}}$ system. We have previously shown that prescribing radiation to the tolerance of dose limiting duodenum can have a favorable toxicity profile in treating pancreas cancer with SBRT(14). Moreover, intrahepatic and hilar tumors are bound to move significantly with respiration, bringing normal tissue within the high dose area if not tracked and adequately accounted for(48-50).

Table 3: Review of Literature.

\begin{tabular}{|c|c|c|c|c|c|c|c|c|c|}
\hline Study & Patients & Localization & $\begin{array}{l}\text { Total } \\
\text { Dose (Gy) }\end{array}$ & Fractions & $\begin{array}{l}\text { Chemotherapy } \\
\text { (CT) }\end{array}$ & $\begin{array}{l}\text { Local Control } \\
\text { (LC) }\end{array}$ & $\begin{array}{l}\text { Overall Sur- } \\
\text { vival (OS) }\end{array}$ & $\begin{array}{l}\text { Median } \\
\text { survival } \\
\text { (months) }\end{array}$ & Toxicity \\
\hline Herfarth & 3 & IHCC & $14-26$ & 1 & No CT & $\begin{array}{l}\text { 1y LC: } 71 \% \\
1.5 y \text { LC: } 67 \%\end{array}$ & Not specified & Not specified & Not specified \\
\hline Tse & 10 & IHCC & $28.2-48$ & 6 & Not specified & 1y LC: $65 \%$ & 1y OS: $57 \%$ & 15 & $\begin{array}{l}2 \text { transient biliary stenosis } \\
2 \text { progressed from Child } A \\
\text { to } B \\
1 \text { small bowel obstruction }\end{array}$ \\
\hline Goodman & 5 & IHCC & $18-30$ & 1 & Not specified & 1y LC: $77 \%$ & $\begin{array}{l}\text { 1y OS: } 71.4 \% \\
2 y \text { OS: } 53.6\end{array}$ & 28.6 & No Grade III toxicity \\
\hline Kopek & 27 & $\begin{array}{l}26 \text { Klatskin } \\
1 \text { IHCC }\end{array}$ & 45 & 3 & No CT & 1y LC: $84 \%$ & Not specified & 10.6 & $\begin{array}{l}6 \text { duodenal/pyloric ulcer } \\
2 \text { duodenal stenosis }\end{array}$ \\
\hline Polistina & 10 & 10Klatskin & 30 & 3 & Gemcitabine & $\begin{array}{l}\text { Local response } \\
\text { ratio: } 80 \%\end{array}$ & $\begin{array}{l}2 y \text { OS: } 80 \% \\
4 y \text { OS: } 30 \%\end{array}$ & 35.5 & $\begin{array}{l}1 \text { duodenal ulcer } \\
2 \text { duodenal stenosis }\end{array}$ \\
\hline Barney & $\begin{array}{l}10(12 \text { le- } \\
\text { sions })\end{array}$ & $\begin{array}{l}6 \text { primary } \\
6 \text { recurrent }\end{array}$ & $55(45-60)$ & 3 or 5 & $\begin{array}{l}8 \text { had CT but not } \\
\text { specified }\end{array}$ & $\begin{array}{l}\text { Local response } \\
\text { ratio: } 100 \%\end{array}$ & $1 y$ OS: $31 \%$ & Not specified & $\begin{array}{l}1 \text { biliary stenosis } \\
1 \text { death due to liver pro- } \\
\text { gression }\end{array}$ \\
\hline Welling & 12 & 12 Klatskin & $50-60$ & 3-5 & Capecitabine & $\begin{array}{l}\text { CR: } 1 / 6 \\
\text { PR: } 4 / 6\end{array}$ & 1y OS: $83 \%$ & Not specified & 14 severe adverse events \\
\hline $\begin{array}{l}\text { Current } \\
\text { study }\end{array}$ & $\begin{array}{l}34 \\
\text { (42lesions) }\end{array}$ & $\begin{array}{l}31 \text { IHCC } \\
11 \text { Klatskin }\end{array}$ & $30(24-45)$ & $3(3-5)$ & $\begin{array}{l}4 \text { Gemcitabine } \\
14 \text { GemCis }\end{array}$ & $\begin{array}{l}1 y r 88 \% \\
4 y r 79 \%\end{array}$ & 1 yr. OS: $58 \%$ & 17 & $\begin{array}{l}\text { 12\% Grade III; } 2 \text { Duodenal } \\
\text { Obstruction, } 2 \text { Infection }\end{array}$ \\
\hline
\end{tabular}

IHCC: Intra Hepatic Cholangio Carcinoma; CT: Chemotherapy; LC: Local Control; OS Overall Survival; CR: Complete Response, PR: Partial Response

\section{Conclusion}

Surgical resection remains the only potential curative treatment for intrahepatic and hilar cholangiocarcinoma. When tumors are unresectable or when resections results in positive margins, outcomes are poor without adjuvant therapy. While conventional chemoradiation and systemic therapy may improve local control and survival it can be arduous and associated with toxicity. SBRT can be an effective and tolerable treatment in this situation.

\section{Competing Interests}

The authors have declared that no competing interest exists.

\section{References}

1. Olnes MJ, Erlich R. A Review and Update on Cholangiocarcinoma. Oncology. 2004;66(3):167-79.

2. de Groen PC, Gores GJ, LaRusso NF, Gunderson LL, Nagorney DM. Biliary tract cancers. N Engl J Med. 1999 Oct 28;341(18):1368-78.

3. Tyson GL, Ilyas JA, Duan Z, Green LK, Younes M, El-Serag HB, et al. Secular Trends in the Incidence of Cholangiocarcinoma in the USA and the Impact of Misclassification. Dig Dis Sci. 2014 Sep 10;

4. Aljiffry M. Advances in diagnosis, treatment and palliation of cholangiocarcinoma: 1990-2009. World J Gastroenterol. 2009 Jan 1;15(34):4240.

5. Robles R, Sánchez-Bueno F, Ramírez P, Brusadin R, Parrilla P. Liver transplantation for hilar cholangiocarcinoma. World J Gastroenterol WJG. 2013 Dec 28;19(48):9209-15

6. Nagorney DM, Donohue JH, Farnell MB, Schleck CD, Ilstrup DM. Outcomes after curative resections of cholangiocarcinoma. Arch Surg Chic Ill 1960. 1993 Aug;128(8):871-7; discussion 877-9.

7. Nagino M, Ebata T, Yokoyama Y, Igami T, Sugawara G, Takahashi Y, et al. Evolution of surgical treatment for perihilar cholangiocarcinoma: a single-center 34-year review of 574 consecutive resections. Ann Surg. 2013 Jul;258(1):129-40. 
8. Crane $\mathrm{CH}$, Macdonald $\mathrm{KO}$, Vauthey JN, Yehuda P, Brown T, Curley S, et al. Limitations of conventional doses of chemoradiation for unresectable biliary cancer. Int J Radiat Oncol Biol Phys. 2002;53(4):969-74.

9. Alden ME, Mohiuddin M. The impact of radiation dose in combined external beam and intraluminal Ir-192 brachytherapy for bile duct cancer. Int J Radiat Oncol Biol Phys. 1994 Mar 1;28(4):945-51.

10. Valle JW, Furuse J, Jitlal M, Beare S, Mizuno N, Wasan H, et al. Cisplatin and gemcitabine for advanced biliary tract cancer: a meta-analysis of two randomised trials. Ann Oncol Off J Eur Soc Med Oncol ESMO. 2014 Feb;25(2):391-8.

11. Mahadevan A, Miksad R, Goldstein M, Sullivan R, Bullock A, Buchbinder E, et al. Induction gemcitabine and stereotactic body radiotherapy for locally advanced nonmetastatic pancreas cancer. Int J Radiat Oncol Biol Phys. 2011;

12. Chang DT, Schellenberg D, Shen J, Kim J, Goodman KA, Fisher GA, et al. Stereotactic radiotherapy for unresectable adenocarcinoma of the pancreas. Cancer. 2009 Feb 1;115(3):665-72.

13. Rusthoven KE, Kavanagh BD, Cardenes H, Stieber VW, Burri SH, Feigenberg SJ, et al. Multi-institutional phase I/II trial of stereotactic body radiation therapy for liver metastases. J Clin Oncol Off J Am Soc Clin Oncol. 2009 Apr 1;27(10):1572-8.

14. Mahadevan A, Jain S, Goldstein M, Miksad R, Pleskow D, Sawhney M, et al. Stereotactic body radiotherapy and gemcitabine for locally advanced pancreatic cancer. Int J Radiat Oncol Biol Phys. 2010;78(3):735-42.

15. DeOliveira ML, Cunningham SC, Cameron JL, Kamangar F, Winter JM, Lillemoe KD, et al. Cholangiocarcinoma: thirty-one-year experience with 564 patients at a single institution. Ann Surg. 2007;245(5):755

16. Farges O, Fuks D, Boleslawski E, Le Treut Y-P, Castaing D, Laurent A, et al. Influence of surgical margins on outcome in patients with intrahepatic cholangiocarcinoma: a multicenter study by the AFC-IHCC-2009 study group. Ann Surg. 2011;254(5):824-30.

17. Nagino M, Kamiya J, Nishio H, Ebata T, Arai T, Nimura Y. Two Hundred Forty Consecutive Portal Vein Embolizations Before Extended Hepatectomy for Biliary Cancer: Surgical Outcome and Long-term Follow-Up. Ann Surg. 2006 Mar;243(3):364-72.

18. Rosen CB, Heimbach JK, Gores GJ. Liver transplantation for cholangiocarcinoma: Transplantation for cholangiocarcinoma. Transpl Int. 2010 Mar 11;23(7):692-7.

19. Forsmo H avard M, Horn A, Viste A, Hoem D, Ovrebo K. Survival and an overview of decision-making in patients with cholangiocarcinoma. Hepatobiliary Pancreat Int. 2008;7(4):412-7.

20. Grove MK, Hermann RE, Vogt DP, Broughan TA. Role of radiation after operative palliation in cancer of the proximal bile ducts. Am J Surg. 1991 Apr;161(4):454-8.

21. Veeze-Kuijpers B, Meerwaldt JH, Lameris JS, van Blankenstein M, van Putten $\mathrm{WL}$, Terpstra OT. The role of radiotherapy in the treatment of bile duct carcinoma. Int J Radiat Oncol Biol Phys. 1990 Jan;18(1):63-7.

22. Brunner TB, Eccles CL. Radiotherapy and Chemotherapy as Therapeutic Strategies in Extrahepatic Biliary Duct Carcinoma. Strahlenther Onkol. 2010 Dec;186(12):672-80.

23. Ghafoori AP, Nelson JW, Willett CG, Chino J, Tyler DS, Hurwitz HI, et al. Radiotherapy in the Treatment of Patients With Unresectable Extrahepatic Cholangiocarcinoma. Int J Radiat Oncol. 2011 Nov;81(3):654-9.

24. Vern-Gross TZ, Shivnani AT, Chen K, Lee CM, Tward JD, MacDonald OK, et al. Survival outcomes in resected extrahepatic cholangiocarcinoma: effect of adjuvant radiotherapy in a surveillance, epidemiology, and end results analysis. Int J Radiat Oncol Biol Phys. 2011 Sep 1;81(1):189-98.

25. Nakeeb A, Pitt H. Radiation therapy, chemotherapy and chemoradiation in hilar cholangiocarcinoma. HPB. 2005 Dec 1;7(4):278-82.

26. Deodato F, Clemente G, Mattiucci GC, Macchia G, Costamagna G, Giuliante F, et al. Chemoradiation and brachytherapy in biliary tract carcinoma: Long-term results. Int J Radiat Oncol. 2006 Feb;64(2):483-8.

27. Montemaggi P, Costamagna G, Dobelbower RR, Cellini N, Morganti AG, Mutignani M, et al. Intraluminal brachytherapy in the treatment of pancreas and bile duct carcinoma. Int J Radiat Oncol Biol Phys. 1995 May 15:32(2):437-43.

28. Takamura A, Saito H, Kamada T, Hiramatsu K, Takeuchi S, Hasegawa M, et al. Intraluminal low-dose-rate 192Ir brachytherapy combined with external beam radiotherapy and biliary stenting for unresectable extrahepatic bile duct carcinoma. Int J Radiat Oncol. 2003 Dec;57(5):1357-65.

29. Foo ML, Gunderson LL, Bender CE, Buskirk SJ. External radiation therapy and transcatheter iridium in the treatment of extrahepatic bile duct carcinoma. Int J Radiat Oncol Biol Phys. 1997 Nov 1;39(4):929-35.

30. Mattiucci GC, Autorino R, Agostino GR D', Deodato F, Macchia G, Perri V, et al. Chemoradiation and brachytherapy in extrahepatic bile duct carcinoma. Crit Rev Oncol Hematol. 2014 Apr;90(1):58-67.

31. González González D, Gerard JP, Maners AW, la Lande-Guyaux B De, Van Dijk-Milatz A, Meerwaldt JH, et al. Results of radiation therapy in carcinoma of the proximal bile duct (Klatskin tumor). Semin Liver Dis. 1990 May;10(2):131-41.

32. Cameron JL, Pitt HA, Zinner MJ, Kaufman SL, Coleman J. Management of proximal cholangiocarcinomas by surgical resection and radiotherapy. Am J Surg. 1990 Jan;159(1):91-7; discussion 97-8.

33. Gerhards MF, van Gulik TM, González González D, Rauws EAJ, Gouma DJ. Results of postoperative radiotherapy for resectable hilar cholangiocarcinoma. World J Surg. 2003 Feb;27(2):173-9.
34. Gwak HK, Kim WC, Kim HJ, Park JH. Extrahepatic bile duct cancers: surgery alone versus surgery plus postoperative radiation therapy. Int J Radiat Oncol Biol Phys. 2010 Sep 1;78(1):194-8.

35. Nelson JW, Ghafoori AP, Willett CG, Tyler DS, Pappas TN, Clary BM, et al. Concurrent Chemoradiotherapy in Resected Extrahepatic Cholangiocarcinoma. Int J Radiat Oncol. 2009 Jan;73(1):148-53.

36. Beltrán $\mathrm{MB}$, Roth $\mathrm{AD}$, Mentha $\mathrm{G}$, Allal AS. Adjuvant radio-chemotherapy for extrahepatic biliary tract cancers. BMC Cancer. 2011;11(1):267.

37. Pitt HA, Nakeeb A, Abrams RA, Coleman J, Piantadosi S, Yeo CJ, et al. Perihilar cholangiocarcinoma. Postoperative radiotherapy does not improve survival. Ann Surg. 1995;221(6):788.

38. Koong AC, Le QT, Ho A, Fong B, Fisher G, Cho C, et al. Phase I study of stereotactic radiosurgery in patients with locally advanced pancreatic cancer. Int J Radiat Oncol Biol Phys. 2004 Mar 15;58(4):1017-21.

39. Schellenberg D, Kim J, Christman-Skieller C, Chun CL, Columbo LA, Ford JM, et al. Single-Fraction Stereotactic Body Radiation Therapy and Sequential Gemcitabine for the Treatment of Locally Advanced Pancreatic Cancer. Int J Radiat Oncol Biol Phys. 2011;

40. Tse RV, Hawkins M, Lockwood G, Kim JJ, Cummings B, Knox J, et al. Phase I Study of Individualized Stereotactic Body Radiotherapy for Hepatocellular Carcinoma and Intrahepatic Cholangiocarcinoma. J Clin Oncol. 2008 Feb 1;26(4):657-64

41. Didolkar MS, Coleman CW, Brenner MJ, Chu KU, Olexa N, Stanwyck E, et al. Image-guided stereotactic radiosurgery for locally advanced pancreatic adenocarcinoma results of first 85 patients. J Gastrointest Surg Off J Soc Surg Aliment Tract. 2010 Oct;14(10):1547-59.

42. Herfarth KK, Debus J, Lohr F, Bahner ML, Rhein B, Fritz P, et al. Stereotactic single-dose radiation therapy of liver tumors: results of a phase I/II trial. J Clin Oncol Off J Am Soc Clin Oncol. 2001 Jan 1;19(1):164-70.

43. Goodman KA, Wiegner EA, Maturen KE, Zhang Z, Mo Q, Yang G, et al. Dose-escalation study of single-fraction stereotactic body radiotherapy for liver malignancies. Int J Radiat Oncol Biol Phys. 2010 Oct 1;78(2):486-93.

44. Polistina FA, Guglielmi R, Baiocchi C, Francescon P, Scalchi P, Febbraro A, et al. Chemoradiation treatment with gemcitabine plus stereotactic body radiotherapy for unresectable, non-metastatic, locally advanced hilar cholangiocarcinoma. Results of a five year experience. Radiother Oncol. 2011 May;99(2):120-3.

45. Barney BM, Olivier KR, Miller RC, Haddock MG. Clinical outcomes and toxicity using Stereotactic Body Radiotherapy (SBRT) for advanced cholangiocarcinoma. Radiat Oncol. 2012;7(1):67.

46. Welling $\mathrm{TH}$, Feng $\mathrm{M}$, Wan $\mathrm{S}$, Hwang SY, Volk ML, Lawrence TS, et al. Neoadjuvant stereotactic body radiation therapy, capecitabine, and liver transplantation for unresectable hilar cholangiocarcinoma: SBRT/Capecitabine and Liver Transplantation for CCA. Liver Transpl. 2014 Jan;20(1):81-8.

47. Kopek N, Holt MI, Hansen AT, H \oyer M. Stereotactic body radiotherapy for unresectable cholangiocarcinoma. Radiother Oncol. 2010;94(1):47-52.

48. Xu Q, Hanna G, Grimm J, Kubicek G, Pahlajani N, Asbell S, et al. Quantifying Rigid and Nonrigid Motion of Liver Tumors During Stereotactic Body Radiation Therapy. Int J Radiat Oncol. 2014 Sep;90(1):94-101.

49. Sterzing F, Brunner TB, Ernst I, Baus WW, Greve B, Herfarth K, et al. Stereotactic body radiotherapy for liver tumors: Principles and practical guidelines of the DEGRO Working Group on Stereotactic Radiotherapy. Strahlenther Onkol. 2014 Oct;190(10):872-81.

50. Schweikard A, Glosser G, Bodduluri M, Murphy MJ, Adler JR. Robotic motion compensation for respiratory movement during radiosurgery. Comput Aided Surg Off J Int Soc Comput Aided Surg. 2000;5(4):263-77. 